\title{
DINAMIKA NOVIČARSKEGA DISKURZA POPULIZMA IN EKSTREMIZMA: MORALNE ZGODBE O BEGUNCIH
}

\author{
Maruša PUŠNIK'
}

COBISS 1.01

\section{IZVLEČEK}

Dinamika novičarskega diskurza populizma in ekstremizma: moralne zgodbe o beguncih Članek proučuje značilnosti ekstremnih populističnih novičarskih diskurzov in njihovih desnih politik na primeru ksenofobnega tona razprav o beguncih in islamu. Da bi demitologiziral populistične diskurze, ki jih reproducirata, in razkril način razširjanja ekstremističnih pogledov, analizira prispevke o beguncih iz dveh tednikov, Reporterja in Demokracije, ki se samoopredeljujeta kot desno usmerjena politična tednika. Njun politični diskurz temelji na avtoritarizmu, militarizmu, nativizmu in etničnem nacionalizmu, kulturalizaciji ekonomske politike in tehniki vzbujanja gnusa in sovraštva namesto sočutja, reartikulira pa se v odnosu do beguncev - migrantov muslimanov, ki ju predstavljata kot nevarnost »našim« svoboščinam. Članek ugotavlja, da islamofobija in ekstremni populistični diskurzi, ki se širijo prek novičarskega diskurza, kulturno zamenjajo z biološkim; nova oblika kulturnega rasizma tudi begunca zamenja z migrantom muslimanom.

KLJUČNE BESEDE: begunci, populistični novičarski diskurz, ekstremizem, nacionalizem, kulturni rasizem

\section{ABSTRACT}

The Dynamics of Journalistic Discourse on Populism and Extremism: Moralistic Stories about Refugees

The article examines the characteristics of extreme populist news discourses and their right-wing policies in the case of xenophobic discussions of refugees and Islam. It analyzes news articles about refugees from two weeklies, Reporter and Demokracija, which are self-described as right-wing-oriented political weeklies, in order to reveal the implementation of their populist policy. This policy is based on authoritarianism, militarism, nativism and ethnic nationalism, the culturalisation of economic policy and on the techniques of arousing disgust and hatred instead of compassion, and it is rearticulated in relation to refugees - Muslim immigrants - who are presented as a threat to "our" freedoms. The article notes that Islamophobia and extreme populist discourses, which are spreading via the news discourse, replace the biological with the cultural, but also refugees with Muslim immigrants, which gives us a new form of cultural racism.

KEY WORDS: refugees, populist news discourse, extremism, nationalism, cultural racism

Dr. komunikologije, izredna profesorica; Univerza v Ljubljani, Fakulteta za družbene vede, Katedra za medijske in komunikacijske študije, Kardeljeva pl. 5, SI-1000 Ljubljana; marusa. pusnik@fdv.uni-lj.si 
Če kmalu ne uspemo izgnati Judov, bodo v zelo kratkem času judaizirali naše ljudi. (Adolf Hitler, govor v Nürnbergu, 13. januar 1923, v Yilmaz 2016: 1)

O muslimanski invaziji na Evropo [...] Do sklepa, da so begunci namerno poslani v Evropo, ni daleč. Zato lepega dne, ko se bomo zbudili, v naši soseski namesto cerkvenega zvonika ne bo samo minaret, ampak bo tudi na naši priljubljeni kavarni pisalo čajnica pri 72 devicah ali pri mučeniku Abdulahu. Takrat bo že zdavnaj prepozno. (Biščak 2015a: 26)

\section{UVOD: MIGRACIJE, NACIONALIZEM IN DESNIČARSKI FENOMEN}

V začetku 21. stoletja se soočamo z množičnim priseljevanjem iz islamskega sveta, kar je posledica konfliktov v deželah, kot so Afganistan, Irak, Somalija, Sirija. ${ }^{1}$ Migracije spremlja porast ekstremnih populističnih diskurzov in politik širom po Evropi in drugod, kar je tesno povezano $\mathrm{z}$ vzponom in s krepitvijo politične desnice in desničarskih, pogosto skrajno ekstremnih diskurzov (Wodak, KhosraviNik 2013; Mammone, Godin, Jenkins 2012; Wilson, Hainsworth 2012; Rydgren 2005; Paxton 2004). Chantal Mouffe (1995; 2005) govori celo o vzponu skrajne desnice in koncu politike, češ da je hegemonsko strategijo namesto socialističnih gibanj prevzela skrajna desnica. Še več, opazni so pereči premiki v oblikah in stilih politične retorike desno usmerjenih strank pa tudi celotnega političnega polja, zato mnogi avtorji opozarjajo, da prihaja do »haiderizacije» in »berlusconizacije» politike in Evrope (Wodak, KhosraviNik 2013: xvii-xviii), kar se odraža v mešanici konzumeristične ideologije, etno-nacionalističnih sentimentov, hedonizma in sovražnosti do manjšin, migrantov in vseh ranljivih skupin. Skupno tem gibanjem je, da spadajo med "gibanja izključevanja in da multikulturalizem vidijo kot sovražnika. Njihovi vodili sta zaustavitev vsakršne migracije in asimilacija že obstoječih migrantov (Rydgren 2005). Meindert Fennema v tej luči ocenjuje:

[...] edino programsko vprašanje, ki je skupno vsem radikalnim desnim strankam, je njihovo zavračanje migrantov in migracijskih politik njihovih vlad. Zato je zavajajoče, da tem strankam pravimo ekstremno desne. Namesto tega jih bomo imenovali antimigracijske stranke. (Fennema 2005: 1)

Nadalje Fennema (2005: 2) trdi, da imajo antimigracijske stranke tri značilnosti: implicitno slavijo fašistično preteklost, zavračajo migracijske politike vlad in slavijo modrost in krepost zdravega razuma in običajnega človeka, zato se kategorije skrajno desnega, rasističnega in populističnega med sabo prepletajo in bi jih bilo težko ločiti. Te stare in nove oblike sovraštva so dandanes uporabljene proti muslimanom. Andrea Mammone, Emmanuel Godin in Brian Jenkins (2012: 4) pravijo, da se krepi »supranacionalni ideal Evrope, ali natančneje sevropski nacionalizem`, kjer je Evropa na splošno veljala kot branik proti amerikanizaciji

$1 \quad$ Za opis zadnje »begunske krize«, kot jo je poimenoval evropski politični vrh in se je začela leta 2015, uporabljam za ljudi, ki so se preseljevali, namesto izraza migrant izraz begunec, saj termin »(i)migrant/priseljenec« ne izraža realne potrebe ljudi po odhodu z ogroženih območij zaradi vojne, konflikta, politične represije, medtem ko se termin »begunec« tega zaveda in to tudi vključuje. 
in komunizmu in, v zadnjem času, proti globalizaciji, ameriški hegemonski moči, multietničnosti in islamu«.

Številni avtorji napovedujejo, da se celotna Evropa premika v desno in se zateka v ektremne populistične diskurze. Ferruh Yilmaz (2016) opozarja, da so populistične skrajne desničarske sile uspele potisniti celotni politični diskurz $\mathrm{v}$ desno natanko z ugrabitvijo debate o migracijah. To dokazuje $z$ vzponom populističnih desnih strank in $s$ tem, da so uspele migracijo iz delavskega vprašanja uspešno obrniti v kulturno grožnjo naciji, kar je posledično premaknilo teren političnega boja iz ekonomije (razredni boj) v kulturo (kulturni boj) in levico in desnico združilo okoli temeljnih vrednot. Premik v desno so olajšale neskončne verige moralnih panik in nasprotij okoli islama in muslimanskih migrantov ter njihovih kulturnih in verskih praks, ki jih slikajo kot grožnjo skupnim dosežkom - razprava o islamu in migrantih se je tako pomaknila $\mathrm{v}$ osrčje evropskih političnih diskurzov (Yilmaz 2012: 368). Islam je postal osrednji politični problem, pogosto povezan z razpravami o terorizmu in varnosti (prav tam). Ksenofobni ton razprav o muslimanskih migrantih in islamu je mnoge raziskovalce napeljal na to, da govorijo o novi obliki rasizma v kulturni preobleki, o kulturnem rasizmu oziroma islamofobiji (Meer, Modood 2009; Yilmaz 2012; Modood 2005; Wren 2001). Mouffe (1995; 2005) razlog za to vidi v političnem vakuumu, ki je nastal kot posledica brisanja levo-desne distinkcije. Tako socialni demokrati kot tudi bolj migrantom prijazne leve stranke si delijo skrajno desničarske skrbi o kulturni grožnji, ki jih muslimanski migranti predstavljajo za »naše» skupne vrednote (Yilmaz 2012: 372). Celotni milje se je glede vprašanj migracije premaknil v desno - gre za odkriti in prikriti rasizem, kot pravi Rodney Coates (2007), pri čemer odkriti rasizem uporablja očitne in zahrbtne oblike, prikriti rasizem pa se skriva za fasado vljudnosti, politične korektnosti, primernosti in objektivnosti (prim. Jontes 2010). Pomik v desno se je zgodil natanko prek debat o nekompatibilnosti muslimanov in islama z evropsko kulturo.

Politični in javni diskurzi so s tem premikom močno ožigosani, kar se navsezadnje odraža tudi v medijskem diskurzu, ki je teme migracij, kulture in vere uspel postaviti kot osrednje zadeve javne debate. ${ }^{2}$ Predvsem je namreč v moči medijev, da ti diskurzi odmevajo po javnem prostoru. Že Stuart Hall in sodelavci (1978) so v sedemdesetih letih prejšnjega stoletja pokazali na moč medijev pri kreiranju moralne panike o rasi in vlogi skrajne desnice pri tem in opozarjali na vlogo medijev, ki nagovarjajo in interpelirajo "mi« skupnost gledalcev tako, da se fokusirajo na raso kot nekaj nenavadnega oziroma to kreirajo kot nenormalno.

Ker je v sodobnem svetu politika mediatizirana, kar pomeni, da postaja odvisna od medijev in da prav mediji postajajo ena najpomembenjših političnih institucij (Mazzoleni, Schultz 1999: 249-251), se tudi desni populizem za svojo odmevnost lahko zahvali predvsem medijskim diskurzom. Ruth Wodak in Majid KhosraviNik (2013: xviii) opozarjata, da je to še zlasti pomembno zaradi naraščajoče splošne apatije širše javnosti do politike, tako da začenjajo ekstremni populistični diskurzi zapolnjevati vrzeli, nastale zaradi razočaranja javnosti nad politiko. Prav splošno nezanimanje za politiko širom po Evropi pa na drugi strani omogoča krepitev populističnih in ekstremističnih diskurzov, ki privilegirajo

2 Antimigrantski diskurzi in ekstremizmi niso nekaj, kar bi se pojavilo ob zadnji »begunski krizi«, ampak jim v novičarskem, medijskem, političnem in nasploh v javnem diskurzu v Sloveniji lahko sledimo ob različnih migracijskih režimih in državnem upravljanju migracijskih procesov skozi zgodovino (glej Doupona, Verschueren, Žagar 2001; Kuzmanić 1999; Vezovnik 2015; Kalc 2016; Pajnik 2011; Milharčič Hladnik 2016). 
šovinistične in nativistične ideologije in krepijo "politiko strahu« (Richardson, Wodak 2009). Za omenjene populistične diskurze je značilna ksenofobna in rasistična propaganda, kar desni populizem ločuje od drugih populizmov; ta namreč polje družbenega na pogosto kontradiktorne načine vzdolž nacionalnih, etničnih, regionalnih in verskih linij ostro dihotomizira $\mathrm{v}$ »mi identiteto « nasproti »oni identiteti« (Wodak, KhosraviNik 2013: xx). KhosraviNik (2009: 480) navaja precejšnje število študij medijskih reprezentacij beguncev, prosilcev za azil in migrantov ter drugih etničnih manjšin, in pravi, da so jim skupne predvsem ugotovitve obstoja strategij negativizacije in kriminalizacije ter poudarjanja vloge kulture kot točke kategorizacije, distanciranja in zvračanja krivde nanje. Paul Hartmann in Charles Husband (1974) sta v sedemdesetih letih prejšnjega stoletja ugotovila, da so reprezentacije migrantov v medijih podobne antisemitskim diskurzom o judovskih migrantih v dvajsetih letih 20. stoletja in da je novičarski diskurz v obeh primerih uporabljal določene ksenofobne argumente. Teun Van Dijk (1987) v tem smislu opozarja, da so migracije in družbeni problemi redefinirani kot rasni problem skupaj z jasno ločnico med »mi/oni«, pri čemer te skupnosti niso reprezentirane kot del »naše« družbe, ampak kot tujci, ki jih je treba »držati zunaj«.

$\mathrm{V}$ članku analiziram kompleksno naravo populistične medijske govorice o beguncih, ki so leta 2015 množično prihajali v Slovenijo in jo večinoma le prečkali. Cilj je pokazati obrise tiste transformacije novičarske govorice, ki je uspela postaviti migracijo, kulturo in vero kot osrednje teme javne debate in je povezana s političnim populizmom ter se najočitneje razgrinja v diskurzu desno usmerjenih medijev. $\mathrm{V}$ ta namen sem pod drobnogled vzela dva politična tednika, Reporter in Demokracijo, ki se samoopredeljujeta kot desno usmerjena in podpirata desno usmerjene politične opcije in svetovne nazore. Ugotoviti poskušam njun način reproduciranja diskurza begunstva in njune morebitne razlike. Razkriti želim značilnosti in mehanizme ekstremne populistične novičarske govorice, ki jo reproducirata in širita v slovenski družbi. Ugotavljanje načina, kako tednika Reporter in Demokracija diskurzivno konstruirata begunce in značilnosti populističnih diskurzov, ki označujejo tovrstno novinarstvo, sta osrednji raziskovalni vprašanji. Robin Wilson in Paul Hainsworth (2012: 17) ugotavljata, da se ključni točki skrajne desnice, migracija in islam, združujeta pri tematiki beguncev, zato se o njih pogosto poroča kot o »tujih « državi gostiteljici. V analizo sem vključila 119 prispevkov o beguncih iz tednika Reporter in 79 prispevkov iz tednika Demokracija, ki so izšli med 20. avgustom in 31. decembrom 2015, v obdobju, ko so begunci prihajali v največjem številu. ${ }^{3} \mathrm{Da}$ bi pokazala, na katere specifične interpretativne repertoarje se pri konstruiranju podob beguncev naslanjajo prispevki iz omenjenih časopisov, uporabljam tekstualno analizo in analizo diskurza. ${ }^{4} \mathrm{~V}$ analizi se osredotočam na prispevke o beguncih in jih obravnavam kot diskurzivne dogodke, ki jim je pomen pripisan v okviru širše diskurzivne formacije. Prispevke obravnavam na semiotski ravni, pri čemer analiziram verbalne pa tudi vizualne kode (fotografije), na ideološki-kontekstualni (diskurzivni) ravni, ko proučujem kode, ki tvorijo diskurze tovrstnega novinarstva, obravnavam pa tudi diskurzivne formacije, ki prek posamičnih diskurzivnih nastopov - prispevkov ustaljujejo specifične pomene o begunstvu v slovenski družbi.

3 Gradivo za analizo sem pridobila od Urada vlade RS za komuniciranje, in sicer vse novinarske prispevke iz tega obdobja, ki so vsebovali besedne korene: $\operatorname{migra}^{\star}$, prebež $\check{z}^{\star}$, begun ${ }^{\star}$.

4 Za podrobnejšo epistemologijo interpretativnih repertoarjev v novinarstvu kot delov širših novinarskih ritualov glej Jontes in Luthar (2015). 


\section{POPULISTIČNO-ETNOKRATIČNI IZZIV IN ETNIČNI NACIONALIZEM: RADIKALIZACIJA KULTURNE RAZLIKE}

Michael Kazin (1995: 3) je populizem definiral kot stil politične/javne retorike, ki mobilizira običajne ljudi nasproti uveljavljenim oblastnim strukturam, dominantnim idejam in vrednotam družbe; to pa je osrednji interpretativni okvir, na katerem temeljita Reporter in Demokracija. Populistična retorika, ki jo reproducirata, vzbuja popularna čustva, jih izkorišča $v$ politične namene in uteleša željo po radikalni spremembi, ki je politična. Kot pravi Hans-Georg Betz (2005: 28), bi bil svet v smislu borbe ljudstva proti kulturnim in političnim elitam lahko drugačen. Ena izmed značilnosti njunega populističnega poročanja o beguncih je antiestablišment oziroma antielitizem. V prispevkih o beguncih se v obeh tednikih nenehno kaže boj ne le proti beguncem, ampak tudi proti kozmopolitskim elitističnim strukturam in, ko govorita o beguncih, se $\mathrm{v}$ člankih v negativnem tonu sklicujeta na varuhinjo človekovih pravic, Amnesty International Slovenije, "nepotešene feministke« (Biščak 2015b: 26), »levosučne medije«, Mirovni inštitut, Svet za odziv na sovražni govor, stranko Združena levica, LGBT gibanja (Kršinar 2015a: 23), evropsko levico, ki »koketira s terorizmom (pri nas somišljeniki titoizma) in je peta kolona v srcu EU« (Ferluga 2015: 8), razne levičarske aktiviste, »ki se kitijo s patetičnimi imeni, recimo protirasistična fronta brez meja" (Sajovic 2015a: 55), Društvo novinarjev Slovenije kot »versko moralno policijo v slogu iranske teokracije, ki nam bo solila pamet, kaj smemo pisati in celo misliti« (Glücks 2015: 20), "prevladujoče promigrantsko razpoložene medije (Biščak 2015c: 11), (levičarske) družboslovce "s svojo sprevrženo logiko, da so poklicani, da razlikujejo med sovražnim govorom in svobodo govora " (Blažič 2015a: 14). Ti prispevki pripovedujejo metazgodbe o beguncih prek kulturnih in političnih elit in s tem domači politični in kulturni teren povezujejo z vprašanjem beguncev. Gre torej za notranji boj proti domačemu sovražniku, kozmopolitskim elitam, in za zunanji boj proti tujemu sovražniku, beguncem.

Tednika Reporter in Demokracija se naslanjata tudi na interpretativne repertoarje avtoritarizma, militarizma in nativizma in jih povezujeta s kombinacijo nacionalizma in ksenofobije (prim. Vezovnik 2015), kar Cas Mudde (2007) označuje kot temeljne značilnosti desnega diskurza. Avtoritarna in militaristična govorica je osrednja diskurzivna strategija pri označevanju beguncev, kar pojasnjuje tudi ostre zahteve po žičnati ograji in dodatni krepitvi vojske in policije v boju proti beguncem. Gre za ustvarjanje militantnega vzdušja, saj je begunec kriminaliziran in prikazan kot ogrožujoči sovražnik domači deželi, proti kateremu se je treba boriti: »Prišlo bo do točke, ko bo potrebna sila - ograja, fizično varovanje meje, vračanje na Hrvaško [...] Ni vprašanje, ali se bo to zgodilo, temveč kdaj« (Glücks 2015: 20). Ali pa gre za slikanje vojaške grožnje interesom domače nacionalne skupnosti:

A samo ograja, pa še tu je vprašanje, kakšno so sploh kupili (če ne gre zgolj za navadne kolute bodeče žice, ki se jih da dokaj enostavno uničiti), ne bo zajezila masovnega dotoka prebežnikov, če meje ne bodo varovale trume policistov in vojakov. [...] Tako veliko število (razočaranih) migrantov v osrčju Evrope pa je prava tempirana bomba, ki se lahko kadarkoli sproži. (Šurla 2015a: 3)

Tak novičarski diskurz ves čas ustvarja vojaške razmere in slika nevarno stanje, $\mathrm{v}$ katerem živimo zaradi prihoda beguncev: 
Povedal bom kar naravnost: razmišljam, da bi si nabavil pištolo. [...] A bom vseeno tvegal, kajti tudi moje zaupanje v voljo in sposobnost države, da mi zagotovi varen in miren vsakdan, je splahnelo. [...] nenadne invazije več milijonov ljudi iz bližnjevzhodnih dežel v Evropo [...] obljublja pol Evrope z ognjem in handžarjem spremeniti v kalifat. (Guzelj 2015: 45)

Tudi stil poročanja je pogosto udarno militanten, s kratkimi in z odrezavimi stavki (prim. Doupona, Verschueren, Žagar 2001), kot na primer: »Prav imajo Slovaki, ki nočejo muslimanov« (Škorc 2015a: 6), ali: »Sama žičnata ograja ni bog ve kaj. Veliko vprašanje je, ali bo sploh zadržala migrante. Verjetno ne« (Berlec 2015: 3). V takšnem populistično militantnem poročanju je problematičen tudi način poimenovanja beguncev, ki jih $\mathrm{z}$ nečloveškimi opisi označujejo kot manjvredne:

[...] ogromne množice tujerodnega prebivalstva, ki prihajajo v Evropo. [...] Zato mora EU drastično spremeniti svojo politiko in odločno zavarovati svoje zunanje meje ter povečati lastno rodnost. V nasprotnem primeru nam grozi propad. Vladavina tujerodne drhali. (Berlec 2015: 3)

Med najbolj razširjenimi populističnimi strategijami v Demokraciji in Reporterju je prav nativizem, ki v prispevkih reproducira populistično trditev, »da imajo določene skupine kulturno identiteto, ki je ni mogoče integrirati, saj naj bi bila nezdružljiva z liberalnimi vrednotami« (Wilson, Hainsworth 2012: 3). Omenjeni populistični diskurzi gredo z roko v roki s sovražnostjo do beguncev in islama. Nacija ima po prepričanju Reporterja in Demokracije namreč biološko konotacijo. Tisti, ki ne pripadajo etnični skupnosti, so izključeni iz nacije. Fennema (2005: 5) pravi, da tak etnični nacionalizem temelji na metafizični nociji, da ima nacija dušo in da je članstvo v njej definirano po sorodstveni liniji, etnični nacionalizem je tako izražen v krvi in tudi v kulturi, pri čemer gre za skupne korenine in za "našost " proti tujstvu (prim. Kuzmanić 1999). Reporter in Demokracija begunce predstavljata kot nezaželene vpadnike, kot nepoštene prosilce za azil in predvsem kot tiste, ki jih je treba odstraniti ali jih zadržati zunaj meja države (prim. Parker 2015: 6-13; za britanski in avstralski tisk). Naj povedano ilustriram z nekaj izbranimi primeri:

Da se bodo v njej integrirali, ni mogoče pričakovati. To niso predsodki, temveč dejstva. (Glücks 2015: 20)

Ampak teh ljudi ni nihče vabil v Evropo. Sami so prišli, zdaj bi pa očitno radi hotele s petimi zvezdicami. Ob vsem še neskončno lažejo. [...] Če komu kaj ni všeč, se lahko obrne in se vrne tja, od koder je prišel, pravijo Posavci, ki nosijo največje breme drugega migrantskega vala. Upajo, da si bodo od teh pritepencev, ki ne znajo drugega kot tožiti, kmalu oddahnili. (Biščak 2015d: 22)

[...] ne gre za spopad civilizacij, pač pa za spopad med civilizacijo in barbarstvom. [...] Je nasprotovanje prihoda beguncev res sovraštvo? [...] Če danes nasprotuješ sprejemu beguncev in priseljencev, si označen za ksenofoba. Če opozarjaš pred nevarnostjo islamizacije, si takoj islamofob. (Blažič 2015a: 14)

S pomočjo tisočev nezakonitih priseljencev, ki vsak dan vdirajo na ozemlje Evropske unije, se rojeva nova Evropa. [...] In kot danes kaže, rezultat tega civilizacijskega trka ne bo evropeizacija 
islama, ampak bomo v naslednjih nekaj destletjih priče islamizaciji Evrope. [...] Nalijmo si čistega vina, kulture niso enakovredne. Zahodna je s svojim humanizmom, zagovorništvom svobode, razuma in dostojanstva posameznika izjemna. Po ekonomskih, tehnoloških in socialnih kazalnikih se v primerjavi z njo islamska izkaže za izrazito manjvredno. Pika. (Brščič 2015: 20)

Bodo Slovenke hodile z naglavnimi rutami? Sloven(islam)ija 2030? Ne! Sam sem za ponosno Slovenijo na veke vekov. [...] A ker je Slovenija integralni del Evropske unije s svojim edinstvenim jezikom, s svojo avtohtono kulturo, s svojim (resda vse prevečkrat skritim) nacionalnim karakterjem, bo hkrati potekal tudi boj za dušo Slovenije. (Kaloh 2015: 8)

Značilnost populističnega diskurza so tudi eksplicitne negativne reprezentacije, ki kriminalizirajo in popolnoma dehumanizirajo begunce (prim. Vezovnik 2015). Begunec v prispevkih Demokracije in Reporterja ni prikazan kot človek, ampak je razčlovečen, večkrat celo animaliziran. Številne so metafore z vodo (begunci so val, poplava, reka), z naravno katastrofo, invazijo in eksodusom, $\mathrm{z}$ velikimi količinami, pri čemer so begunci prikazani kot vzrok za strah, stres in nevarnost (prim. Doupona, Verschueren, Žagar 2001; prim. KhosraviNik 2009: 484-491; za britanski tisk) - reka ilegalnih migrantov, begunski roj« (Biščak 2015a: 26), "val migrantov, volkovi iz Evrabije (Šurla 2015b: 3), "priseljeniški roj, podivjana drhal« (Biščak 2015e: 24), »begunski cunami« (Reporter 2015: 15), »roj prišlekov vidijo kot invazijo na slovensko zemljo [...] prevladujejo moški, ki so nadležni kot roj mušic« (Biščak 2015d: 22), »zlasti v zadnjem letu pa se je `snežna kepa‘ prebežnikov [...] začela valiti vse hitreje in se debeliti do neslutenih razsežnosti« (Kavčič 2015: 7), »invazijci« (Sajovic 2015a: 55). Tovrstne opise v Reporterju in Demokraciji spremljajo izključno fotografije množice beguncev, kjer je poudarjena masa ljudi, ne pa begunec kot posamični človek.

Prevladuje argumentacija pozitivne samoreprezentacije, ki je postavljena nasproti negativni reprezentaciji Drugih - beguncev. Negativne reprezentacije beguncev se nanašajo na skupne topike, vključujoč številke, grožnje (kulturni identiteti, skupnostnim vrednotam) in nevarnost. Begunci so konstruirani kot razčlovečena homogena skupina, ki si prek procesov agregacije, kolektivizacije in posploševanja deli podobne značilnosti, ozadja, motivacije. V tej luči je zelo pogost tudi fokus na nasilje in spolne zlorabe, vse to pa je predstavljeno v okviru kriminaliziranja beguncev in zastraševalnega diskurza. Naj to ilustriram z nekaj primeri:

Evropa je v vojni in Slovenija z njo. [...] Povsod po Evropi, kjer so taki centri, migranti, ker ni po njihovem, postanejo nasilni, vlamljajo, ropajo in posiljujejo. [...] Zato lahko upravičeno sklepamo, da se utegne tudi v Sloveniji dobrota izkazati za siroto, teroristična grožnja državi se bo povečala. (Biščak 2015f: 42)

Ker dobršen del teh prihaja z Bližnjega vzhoda, se kažejo vzporednice z nekdanjimi turškimi vpadi v Evropo. [...] Nemir se je preselil tudi na državljane. In nehote se je sprožil »zgodovinski spomin« izpred stoletij. Iz časa turških vpadov. (Sajovic 2015a: 55)

[...] da so le-ti huda grožnja za nas in da jim bo presenetljivo hitro uspelo islamizirati Evropo do mere, ko bodo kristjani prisiljeni boriti se za svoje pravice. (Škorc 2015b: 6) 
Betz (2005: 32) omenjene značilnosti populizma označuje kot etnokratični izziv, saj takšni medijski diskurzi ponujajo transformacijo liberalne demokracije v etnokracijo, ki daje absolutno prioriteto varovanju interesov »svojih ljudi« in zaščiti nacionalne kulture in identitete. Kot ugotavlja, termin etnokracije popolnoma zaobjame bistvo radikalnega populističnega desnega političnega projekta, kot da gre za predvideno obnovo zahodnih demokracij. $\mathrm{Z}$ drugimi besedami, gre za obrambo nacionalne identitete, predvsem $\mathrm{v}$ smislu ubranitve "naših vrednot, naših običajev in našega načina življenja«. Gre za mehanizme distance in cinizma do tujega, od koder črpa populistični diskurz Reporterja in Demokracije, s katerim bralci poenostavljajo kompleksnost sveta. Ta mehanizem uporabljajo avtorji prispevkov, saj se namesto k raziskovanju nepoznanega in h kontekstualiziranju drugačnosti zatekajo $\mathrm{k}$ radikalizaciji kulturnih razlik in h konstrukciji hierarhij - »našost « je drugačna in večvredna od tujosti. Reproduciranje distance v prispevkih pa disciplinira bralce/ke kot pripadnike določene kolektivitete, saj postavlja ekskluzivni okvir za interpretacijo - vzbuja strah in gnus pred begunci ter hkrati simpatijo in sočustvovanje $\mathrm{z}$ domačini (za zgodovinski pregled migracijskih režimov prim. Kalc 2016). Mammone, Godin in Jenkins (2012: 3) pravijo, da je vznik nacionalističnih gibanj, ki v središče kot ključni element politične retorike in razvoja politične agende postavljajo prav nacijo, paradoks sodobnosti. Nacija kot zamišljena domovina je tako še vedno ključni koncept. Še več, s krepitvijo nacije nastaja transnacionalni politični prostor ali transnacionalni evropski prostor (Mammone, Godin, Jenkins 2012: 5). Rasizem in nacionalizem sta v Reporterju in Demokraciji tesno povezana in - ko se begunce sooča $\mathrm{z}$ vrednotami, s tradicijami in kulturami domovine - vztrajata pri obrambi monoetnične skupnosti. V reprezentacijah Reporterja in Demokracije je Evropa pogosto predstavljena kot obsojeni kontinent, ki je zaradi koordiniranih kampanj islamizacije na robu kulturnega izumrtja (prim. Carr 2006). Evrabijske fantazije, kot jih poimenuje Yilmaz (2012: 370), tako begunce nenehno sprevračajo v tujo grožnjo.

\section{ŠOVINISTIČNI OKVIR DRŽAVE BLAGINJE: KULTURALIZACIJA EKONOMSKE POLITIKE}

Jens Rydgren (2005) pravi, da se diskurz antimigracijske populistične politike napaja tudi iz šovinističnega okvira države blaginje - resnični ali domnevni stroški migracij so razumljeni kot grožnja programom države blaginje zahodnih družb. Avtorji prispevkov namreč prikazujejo, da se zaradi prihoda beguncev reducira socialna varnost slovenskih državljanov, da ti zaradi beguncev ne bodo dosegali socialne blaginje, ki se nanaša na nacionalni minimum dobrin in storitev. ${ }^{5}$ Reporter in Demokracija v prispevkih begunce poudarjeno prikazujeta kot ekonomske migrante, ki kot paraziti črpajo državne zaloge:

Že sama logika pove, da so to v veliki večini ekonomski migranti, ki iščejo boljše življenje, ne pa begunci, ki bežijo pred vojno. V vseh državah, ki jih prečkajo, ni vojne, tam pa ne bi ostali, ker so zanje prerevne, vključno s Slovenijo. [...] Če ne bomo zaprli svoje južne meje, bomo v najslabšem

5 Da na primer begunci s svojim prihodom ogrožajo zagotavljanje minimalnega dohodka slovenskim državljanom in da kot finančno breme ogrožajo sistem zdravstvenega varstva in pokojninske varnosti v državi. 
črnem primeru postali »begunska« tamponska cona. Migranti bodo besni hoteli v Avstrijo, tja pa ne bodo mogli več, zato bodo verjetno razgrajali po Sloveniji. (Kršinar 2015b: 26)

Begunci so v prispevkih prikazani kot nelegitimni tekmovalci za državna sredstva in kot tisti, ki lahko povečajo nezaposlenost v državi:

Če pa bodo begunci le poležavali ob brezplačni hrani, se jim bodo začeli po glavi poditi ekstremizmi. [...] Cerar o zaposlitvi beguncev tudi ne govori, saj dobro ve, da imamo doma kar 110.000 brezposelnih. (Sajovic 2015b: 14)

Fennema (2005: 14-15) pripominja, da so prav ekonomski interesi tista pomembna spremenljivka, ki omogoča uspešnost antimigracijskih politik širom po Evropi (prim. Kuzmanić 1999; Vezovnik 2015), ${ }^{6}$ Yilmazova študija pa prinaša zanimive zaključke o tem, kako deluje rasizem v odnosu zahodnih evropskih držav do islamskih migrantov.

$\mathrm{V}$ tem procesu se je transformirala sama kategorija migrant: migrant delavec se je spremenil $\mathrm{v}$ migranta muslimana. Ni bila kulturalizirana le kategorija migranta; debata o kulturalizirani migraciji je zavzela osrednje mesto v političnem diskurzu. (Yilmaz 2012: 370)

Soysal (2009: 5-7) zatrjuje, da je kultura postala glavni način naslavljanja državljanstva, varnosti in ekonomije, ki so bili, konvencionalno gledano, obravnavani kot ločeni od kulture. Še več, po Yilmazu (2012: 370) je kultura islama postala zdravi razum v urejanju, organiziranju in upravljanju gospodarskih odnosov in sveta, kjer muslimani nadomeščajo migrante, ti pa begunce. Reporter in Demokracija torej ekonomsko vprašanje reducirata na kulturno vprašanje, kjer begunce najprej predstavljata kot izključno ekonomske migrante, ki napadajo ekonomske okvire domače države, ker mora država zanje odšteti precej denarja, nato pa vse to zreducirata na kulturno vprašanje - na muslimana, ki napada ne le ekonomske, ampak tudi kulturne in varnostne temelje slovenske/evropske družbe. Begunec je torej dvojno degradiran, najprej je označen zgolj za ekonomskega migranta in nato za muslimana, ki predstavlja grožnjo evropski skupnosti. Diskurz begunstva je kulturaliziran, ko je kategorija begunca skrčena na ekonomsko breme in na varnostno grožnjo. Za ilustracijo navajam dva konkretna primera:

Po svoje imamo srečo, da se za migrante Evropa začne šele v Šentilju in da je le za vzorec tistih, ki v Sloveniji zaprosijo za azil. [...] Koliko deset tisoč migrantov bo potem ostalo pri nas in kako bo to na plečih davkoplačevalcev reševala vlada, nihče ne ve. (Šurla 2015c: 3)

[...] zato je veliko bolj verjetno, da gre za dobro organiziran, obilno financiran in skrbno načrtovan migrantski val. [...] teza o načrtovani invaziji muslimanov v Evropo ni iz trte izvita. (Blažič 2015b: 16)

6 Kot kažejo študije po Evropi, volivci podpirajo skrajne desničarske stranke ne le iz ideoloških razlogov, ampak tudi iz zelo pragmatičnih razlogov in rešitev, ki jih te stranke ponujajo (Betz 2005: 32-35). 


\section{ONKRAJ POSTHUMANITARNE SENZIBILNOSTI: SOČUTJE KOT GNUS IN SOVRAŠTVO}

"Že nekaj tednov sem namreč razmišljala, da bi pomagala - ne samo migrantom, ampak prostovoljcem, ki so utrujeni, neprespani in se ob vsem tem še vedno trudijo, da bi za begunce čim bolje poskrbeli« (Opeka 2015: 30). To je temeljna oblika vzbujanja senzibilnosti med bralci/kami, kot jo prikazujejo prispevki Reporterja in Demokracije. Za kaj pravzaprav gre?

Chouliaraki (2008) ugotavlja, da nas v času posthumanitarne senzibilnosti reprezentacije trpljenja oddaljenih Drugih bolj zabavajo, kot pa da bi v nas spodbudile solidarne javne akcije, kar veliko pove o tem, v kakšne odnose stopamo z oddaljenimi Drugimi. V globalnem kontekstu in v mediatizirani družbi smo množično vsak dan soočeni z Drugimi, ki trpijo, ne da bi imeli možnost odreagirati na njihovo situacijo, čemur Tomlinson (1999) pravi, da prihaja do deteritorializacije izkušnje (prim. za slovenske primere Vezovnik 2015; Milharčič Hladnik 2016; Pajnik 2011). Še več, Reporter in Demokracija celo povsem eksplicitno promovirata indiferentnost, apatijo in očitno averzijo, gnus ter sovraštvo do teh oddaljenih Drugih - beguncev. Na primer: »Seveda, ko na ekranu vidiš uboge mokre, lačne in premražene otroke, te stisne pri srcu. Če te ne bi, nisi človek. Toda kdor ne vidi širše slike, ne vidi ničesar. Tudi otroci so orožje za hitrejšo dosego cilja« (Glücks 2015: 20). Populistični diskurz Reporterja in Demokracije se namreč v bralcih/kah niti ne trudi vzbujati sočutja, ampak s tem, ko svoja občinstva izpostavlja številnim vizualnim podobam človeške tragedije in trpljenja (fotografije množice beguncev), na ravni teksta pa jim ponuja podobe gnusa, odpora in sovraštva do beguncev, deluje kot javni spektakel. Bralcem/kam sugerira, kako naj o beguncih razmišljajo in čutijo:

Čeprav so mediji polni srce parajočih fotografij žensk in otrok, ki naj bi bili v večini, tega nismo videli [...] ti ljudje večinoma niso nikakršni begunci, ampak ekonomski migranti. [...] Zgodbe vseh pa so bolj ali manj enake: vsi so iz Sirije, življenje vseh je bilo ogroženo, če ne bi odšli, bi lahko ostali brez glave ali bi jih zadela bomba. Tudi njihovi očitki in pripombe so si na las podobni: vsi so utrujeni, lačni in žejni, vsem ni jasno, zakaj se po Evropi ne morejo prosto sprehajati, zakaj morajo tako dolgo čakati, zakaj ni zanje boljše preskrbljeno, zakaj so sploh potrebni dokumenti, saj so ubogi begunci, in zakaj morajo hoditi, če bi se lahko peljali z avtobusi ali vlaki. (Biščak 2015g: 22)

Kot bi rekla Susan Sontag (2003), gre na ravni fotografij množice beguncev sicer za klinično narativizacijo trpljenja, za nekaj, kar je daleč od nas in irelevantno. To pa še dodatno blokira povezljivost gledalca/ke in tistega, ki trpi. Gledalec/ka namreč ob ponavljajočih se fotografijah zasede aktersko pozicijo voajerja, priče, osvobojene moralne dolžnosti delovanja, zato v naslonjaču lahko udobno uživa ob medijskih podobah (prim. Chouliaraki 2008: 842-843). Populistični diskurz Reporterja in Demokracije se v bralcih/kah niti najmanj ne trudi izzvati sočutja do ljudi, ampak jih, nasprotno, zabava z eksplicitnimi opisi averzije in gnusa do njih. Po Kevinu Robinsu (1994: 464) prihaja do "fantazmagoričnega učinka«, ko trpljenje Drugih postaja senzacija. Ponavljanje podob trpljenja pri bralcih/kah vzbuja predvsem odpor, ne pa sočutja. Reprezentacije trpljenja drugih bralce/ke ohranjajo na varni distanci, kar jim omogoča, da se prepustijo »emocionalni simpatiji«, ne da bi njihovo varno izoliranost ogrozila realnost trpečih drugih (Žižek 2002: 291). 
Prispevki Reporterja in Demokracije privilegirajo »naše» ljudi (Karitas, Rdeči križ, prostovoljce, policaje, vojake itd.) in sočutje do beguncev nadomeščajo s sočutjem do njih. Kot na primer:

\begin{abstract}
V največjem begunskem valu po drugi svetovni vojni v Evropi, po podatkih policije je v nekaj dneh prestopilo slovensko mejo več kot 3600 migrantov in beguncev, so se izkazale posamezne dobrodelne in humanitarne organizacije. V sodelovanju z Upravo za zaščito in reševanje, slovenskimi skavti in številnimi prostovoljci je izstopala, tako kot že velikokrat doslej, Slovenska Karitas, zaupanje pri zbiranju pomoči beguncem so si pridobili tudi člani Društva Adra. (Karneža Cerjak 2015a: 45)
\end{abstract}

Prispevki objavljajo personalizirane zgodbe »naših« ljudi, ki izzovejo veliko mero sočutja pri bralcih/kah, tako da se z njimi zlahka identificirajo in sočustvujejo. Ni pa podobnih zgodb o beguncih, s katerimi bi predstavili njihove osebne zgodbe, personalizirane zgodbe malega človeka - begunca. Predstavljajo jih izključno kot maso ljudi, ki pritiska na Slovenijo/Evropo, tako da tak populistični diskurz v bralcih/kah namesto sočutja izzove zgolj gnus in odpor, hkrati pa bralcem/kam ponuja položaj državljanov - agresivnih voajerjev. Pogoste so fotografije beguncev, ki prikazujejo način dela članov humanitarnih organizacij z njimi, kot npr. Karitas, UNHCR, ti držijo v rokah dojenčke in otroke itd. (Karneža Cerjak 2015b: 49). V ospredju so torej prostovoljci, ki se jim izkazuje sočutje. Prikazani so kot tisti, ki se brezmejno žrtvujejo, begunec pa je samo kulisa, kot tisti, ki stoji tam, da bralci/ke lahko sočustvujejo z domačini, ki morajo delati z njimi. Osrednji moto takega populističnega diskurza je torej prikazovanje humanitarne krize kot varnostne krize, kjer sta pomoč beguncem in sočutje do njih zamenjala pomoč prostovoljcem in sočutje predvsem do njih in lastne države: »Ekipe so izredno obremenjene, zato pričakujejo drugačne rešitve. Karitas in prostovoljci. [...] Redno delo občinske Karitas je ohromelo, občani so deležni manj pomoči, kot bi je bili v normalnih razmerah« (Kocjan 2015: 33).

\title{
ZAKLJUČEK: POPULIZEM KOT KULTURNI RASIZEM
}

Pri islamofobiji in ekstremnih populističnih diskurzih, ki se širijo prek novičarskega diskurza, gre za zamenjavo biološkega s kulturnim, begunca z ekonomskim migrantom in muslimanom, pri čemer ima rasizem drugačno ime ali pa je skrit (prim. Kuzmanić 1999; Doupona, Verschueren, Žagar 2001). Yilmaz (2008: 370) govori o rasizmu v novi, »kulturni preobleki«. Van Dijk (1991: 25; glej tudi Billig 2006) je že pred leti opozarjal na premik k novemu rasizmu, ko pri konstruiranju »nas« nasproti »onim« prihaja do premika od rase h kulturi. Pojavljajo se novi načini artikuliranja »mi« skupnosti - evropske civilizacije proti islamu, kjer postaja "našost« srž nacionalnih skupnosti, ki se krepijo. V članku ugotavljam, da tednika Reporter in Demokracija v tem oziru izvajata populistično politiko, ki temelji na mehanizmih ekstremne populistične novičarske govorice, kot so avtoritarizem, militarizem, nativizem in etnični nacionalizem, kulturalizacija ekonomske politike in namesto sočutja na tehniki vzbujanja gnusa in sovraštva. Ta politika se reartikulira v odnosu do beguncev, ki so predstavljeni kot nevarnost za "naše» svoboščine. Med tednikoma Reporter in Demokracija v reproduciranju ekstremnih populističnih diskurzov ni razlike, še več, ob poročanju o begunstvu sta oba uspela postaviti teme o kulturi in veri beguncev 
kot osrednje zadeve javne debate. Ugotavljam, da so begunci v novinarstvu Reporterja in Demokracije diskurzivno konstruirani le v okviru ogrožujočega islama in muslimanske kulture, skoraj nikoli pa ne spregovori o vojnih razmerah in političnih konfliktih, zaradi katerih so se preselili, pri čemer so begunci povsem razčlovečeni in prikazani le kot grožnja slovenski državi.

Novinarstvo, ki ga po javnem prostoru razširjata Reporter in Demokracija, temelji na kulturaliziranem političnem diskurzu:

Kar je bila tradicionalna delitev med kapitalom in delavstvom, ki je nekoč formirala obrise levice in desnice v Evropi, je to danes kulturna delitev med nacionalnimi državljani na eni strani in kozmopolitskimi kulturnimi elitami in muslimanskimi migranti na drugi. (Yilmaz 2012: 372-373)

To je nova retorika izključevanja, značilna za populistične diskurze, kot jih reproducirata tudi Reporter in Demokracija in so po Vereni Stolcke (1995) splošna značilnost desne politike. Islamofobne kampanje so namreč postale nov zaščitni znak desnice širom po Evropi (Mammone, Godin, Jenkins 2012: 6). Še več, prihaja do novega hegemonskega premika - ideje, ki so bile nekoč obravnavane na ekstremnem desnem koncu političnega spektra (npr. islam kot inkompatibilen $\mathrm{z}$ evropskimi vrednotami), so se pomaknile v sam center in so jih posvojile tako mainstream desne kot leve politične skupine (prim. Yilmaz 2012: 373). S tem prihaja tudi do visoke atomizacije družbe, s katero je že Hannah Arendt (1973: 352) pojasnjevala vzpon Hitlerjeve NSDAP in sovraštva do Judov - govorila je o družbeni dezintegraciji. Po njenem mnenju so lahko le množice visoko atomizirane družbe sprejele tako nasilen nacionalizem, družbena izolacija namreč med množicami ustvarja samodestruktivne in iracionalne impulze. To pa pojasnjuje vzpon in krepitev ekstremnega populizma kot novega kulturnega rasizma.

Ta reartikulacija se v Evropi dogaja s pomočjo debat o migrantih in islamu ter ideološko proizvedenih povezav med islamom kot grožnjo in terorizmom, kar potrjuje tudi analiza prispevkov o beguncih v Reporterju in Demokraciji. Yilmaz (2012: 374) meni, da je zahodna civilizacija $\mathrm{v}$ obeh primerih predstavljena kot pogoj za realizacijo emancipatornih projektov. Tako Reporter kot Demokracija namreč reproducirata islamofobne/ksenofobne perspektive in prav na tak način se kulturalizirajo tudi rasistične hegemonske artikulacije, ki simbolno vpisujejo »Evro-islam razcep« v samo središče družbe. Proti takim ekstremnim populističnim diskurzom pa se je treba vztrajno boriti z antinacionalističnimi hegemonskimi projekti, ki bi nenehno razkrinkavali kulturno rasistično govorico $\mathrm{v}$ novinarstvu, zaradi česar potrebujemo tudi ostro kozmopolitsko držo. Če parafraziram Ulricha Becka in Edgarja Grandeja (2006), potrebujemo politično filozofijo ustavne strpnosti, ki bi zagotovila, da je prav nevtralno stanje lahko dom posameznikov različnih nacionalnih pripadnosti.

\section{LITERATURA}

Arendt, Hannah (1973). The origins of totalitarianism. Orlando: Harcourt Brace \& Company. Beck, Ulrich, Grande, Edgar (2006). Cosmopolitan Europe. Cambridge: Polity Press. 
Betz, Hans-Georg (2005). Against the system: Radical right-wing populism's challenge to liberal democracy. Movements of Exclusion: Radical Right-Wing Populism in the Western World (ur. Jens Rydgren). New York: Nova Science Publishers, 25-40.

Billig, Michael (2006). Political Rhetorics of Discrimination. Elsevier Encyclopaedia for Language and Linguistics. Oxford: Elsevier.

Carr, Matt (2006). You are now entering Eurobia. Race and Class 48/1, 1-22.

Chouliaraki, Lilie (2008). The media as moral education: Mediation and action. Media, Culture and Society 30/6, 831-852.

Coates, Rodney D. (2007). Covert Racism in the USA and Globally. Sociology Compass 2/1, 208-231.

Doupona, Marjeta, Verschueren, Jef, Žagar, Igor Ž. (2001). Retorika begunske politike v Sloveniji: Pragmatika legitimizacije. Ljubljana: Mirovni inštitut.

Fennema, Meindert (2005). Populist parties of the right. Movements of Exclusion: Radical Right-Wing Populism in the Western World (ur. Jens Rydgren). New York: Nova Science Publishers, 1-24.

Hall, Stuart, Critcher, Chas, Jefferson, Tony, Clarke, John, Brian, Roberts (1978). Policing the Crisis: Mugging, the State, and Law and Order. London, Basingstoke: Macmillan Press.

Hartmann, Paul, Husband, Charles (1974). Racism and the Mass Media. London: Davis-Poynter.

Jontes, Dejan (2010). Slovenian sitcom and the construction of otherness. Cultural Studies $24 / 5,716-728$.

Jontes, Dejan, Luthar, Breda (2015). Epistemology of journalistic rituals: The case of domestic violence. Anthropological Notebooks 21/3, 21-37.

Kalc, Aleksej (2016). Nadzor migracijskih gibanj in migrantov: Pogled v zgodovino. Dve domovini / Two Homelands 43, 23-34.

Kazin, Michael (1998). The Populist Persuasion: An American History. Ithaca: Cornell University Press.

KhosraviNik, Majid (2009). The representation of refugees, asylum seekers and immigrants in British newspapers during the Balkan conflict (1999) and the British general election (2005). Discourse \& society 20/4, 477-498.

Kuzmanić, Tonči (1999). Bitja s pol strešice: Slovenski rasizem, šovinizem in seksizem. Ljubljana: Open Society Institute.

Mammone, Andrea, Godin, Emmanuel, Jenkins, Brian (2012). Mapping the 'right of the mainstream right' in contemporary Europe. Mapping the Extreme Right in Contemporary Europe: From Local to Transnational (ur. Andrea Mammone, Emmanuel Godin, Brian Jenkins). New York: Routledge, 1-14.

Mazzoleni, Gianpetro, Schultz, Winfried (1999). Mediatization of Politics: A Challenge for Democracy? Political Communication 16/3, 247-261.

Meer, Nasar, Modood, Tariq (2009). The racialisation of Muslims. Thinking Through Islamophobia (ur. Salman Sayyid, Abdoolkarim Vakil). London: C. Hurst, 69-84.

Milharčič Hladnik, Mirjam (2016). Nadzor nad nadzorom: Strategije upiranja in avtonomnost delovanja migrantk v sodobni in zgodovinski perspektivi. Dve domovini / Two Homelands 43, 35-46.

Modood, Tariq (2005). Multicultural Politics: Racism, Ethnicity, and Muslims in Britain. Minneapolis: The University of Minnesota Press.

Mouffe, Chantal (1995). The end of politics and the rise of the radical right. Dissent, 498-502. 
Mouffe, Chantal (2005). On the Political. London: Routledge.

Mudde, Cas (2007). Populist Radical Right Parties in Europe. Cambridge: Cambridge University Press.

Pajnik, Mojca (2011). Narrating Belonging in The Post-Yugoslav Context. Dve domovini / Two Homelands 34, 111-125.

Parker, Samuel (2015). 'Unwanted invaders': The representation of refugees and asylum seekers in the UK and Australian print media. eSharp 23, Myth and Nation, http:// www.gla.ac.uk/media/media_404384_en.pdf (26.6. 2016).

Paxton, Robert (2004). The Anatomy of Fascism. London: Vintage.

Richardson, John E., Wodak, Ruth (2009). The impact of visual racism: Visual arguments in political leaflets of Austrian and British far-right parties. Controversia 6/2, 45-77.

Robins, Kevin (1994). Forces of Consumption: From the Symbolic to Psychotic. Media, Culture \& Society 16/4, 449-468.

Rydgren, Jens (ur.) (2005). Movements of Exclusion: Radical Right-Wing Populism in the Western World. New York: Nova Science Publishers.

Sontag, Susan (2003). Regarding the Pain of the Others. New York: FSG Books.

Soysal, Levent (2009). Introduction: Triumph of culture, troubles of anthropology. Focaal - European Journal of Anthropology 55, 3-11.

Stolcke, Verena (1995). Talking Culture: New Boundaries, New Rhetorics of Exclusions in Europe. Current Anthropology 36/1, 1-24.

Tomlinson, John (1999). Globalization and Culture. London: Sage.

Van Dijk, Teun A. (1987). Communicating Racism: Ethnic Prejudice in Thought and Talk. Newbury Park, CA: Sage.

Van Dijk, Teun A. (1991). Racism and the Press: Critical Studies in Racism and Migration. London, New York: Routledge.

Vezovnik, Andreja (2015). Ex-Yugoslavian Immigrant Workers in Slovenia: Between Balkanization and Victimization. Dve domovini / Two Homelands 41, 11-22.

Wilson, Robin, Hainsworth, Paul (2012). Far-right parties and discourse in Europe: A challenge for our times. European Network Against Racism. Bruselj, http://cms.horus.be/ files/99935/MediaArchive/publications/20060_Publication_Far_right_EN_LR.pdf (20. 6. 2016).

Wodak, Ruth, KhosraviNik, Majid (2013). Dynamics of discourse and politics in right-wing populism in Europe and beyond: An introduction. Right-wing Populism in Europe: Politics and Discourse (ur. Ruth Wodak, Majid KhosraviNik, Brigitte Mral). London: Bloomsbury, xvii-xxviii.

Wren, Karen (2001) Cultural racism: Something rotten in the state of Denmark? Social and Cultural Geography 2/2, 141-162.

Yllmaz, Ferruh (2011). The politics of the Danish cartoon affair: Hegemonic intervention by the extreme right. Communication Studies 62/1, 5-22.

Yilmaz, Ferruh (2012). Right-wing hegemony and immigration: How the populist far-right achieved hegemony through the immigration debate in Europe. Current Sociology $60 / 3,368-381$.

Yilmaz, Ferruh (2016). How the Workers Became Muslims: Immigration, Culture and Hegemonic Transformation in Europe. Ann Arbor: The University of Michigan Press.

Žižek, Slavoj (2002). Edini dobri bližnjik je mrtvi bližnjik. Problemi 40/1-2, 281-301. 


\section{ANALIZIRANI VIRI}

Berlec, Metod (2015). Se bliža vladavina drhali? Demokracija, 19. 11., 3.

Biščak, Jože (2015a). Čajnica pri 72 devicah. Reporter, 10. 8., 26.

Biščak, Jože (2015b). Jaz rasist. Reporter, 31. 8., 26.

Biščak, Jože (2015c). Migranti kradli v vrhniški trgovini. Reporter, 21. 12., 11.

Biščak, Jože (2015d). To se ne bo dobro končalo. Reporter, 2. 11., 22.

Biščak, Jože (2015e). To je spopad civilizacij. Reporter, 31. 8., 24.

Biščak, Jože (2015f). Stalni centri bodo resna teroristična grožnja. Reporter, 23. 11., 42.

Biščak, Jože (2015g). En dan z migranti in policisti. Reporter, 26. 10., 22.

Blažič, Gašper (2015a). Na pragu novega trka civilizacij? Demokracija, 6. 8., 14.

Blažič, Gašper (2015b). Grenka resnica o migrantih. Demokracija, 24. 9., 16.

Brščič, Bernard (2015). EUrabia ali Dar-el-Harb? Demokracija, 10. 9., 20.

Ferluga, Pavel (2015). V božjem imenu. Demokracija, 27. 8., 8.

Glücks, Nenad (2015). Vojna, v kateri je orožje masa ljudi. Reporter, 26. 10., 20.

Guzelj, Igor (2015). Revščina v glavah. Reporter, 26. 10., 45.

Kaloh, Dejan (2015). Rdeči alarm za slovensko identiteto. Demokracija, 12. 11., 8.

Karneža Cerjak, Biserka (2015a). Humanitarci na meji. Reporter, 28. 9., 45.

Karneža Cerjak, Biserka (2015b). Slovenci smo solidaren narod, vedno bomo priskočili na pomoč. Reporter, 7. 9., 49.

Kavčič, Lucija (2015). Je trojanski konj že v EU? Demokracija, 27. 8., 7.

Kocjan, Vida (2015). Brežice: Z dnevnimi prihodi migrantov najbolj obremenjena občina. Demokracija, 5. 11., 33.

Kršinar, Igor (2015a). Obračun s svobodo govora. Reporter, 7. 9., 23.

Kršinar, Igor (2015b). Zid na Kolpi. Reporter, 12. 10., 26.

Opeka, Maruša (2015). Kot prostovoljka v zbirnem centru. Demokracija, 5. 11., 30.

Reporter (2015). Vlada v časovnem zamiku. Reporter, 26. 10., 15.

Sajovic, Bogdan (2015a). Turška invazija na Evropo. Demokracija, 24. 9., 55.

Sajovic, Bogo (2015b). Kakšne begunce bi sprejeli? Reporter, 7. 9., 14.

Škorc, Aleksander (2015a). Pogled nad pogledi. Demokracija, 10. 9., 6.

Škorc, Aleksander (2015b). Skrajno dobro. Demokracija, 1. 10., 6.

Šurla, Silvester (2015a). Invazija. Reporter, 9. 11., 3.

Šurla, Silvester (2015b). Volkovi iz Evrabije. Reporter, 31. 8., 3.

Šurla, Silvester (2015c). Kamele ob Renu. Reporter, 26. 10., 3. 


\section{SUMMARY}

\section{THE DYNAMICS OF JOURNALISTIC DISCOURSE ON POPULISM AND EXTREMISM: MORALISTIC STORIES ABOUT REFUGEES}

\section{Maruša PUŠNIK}

This article investigates the characteristics of extreme populism in journalism in the case of xenophobic discussions of refugees and Islam, which is being spread around Slovenia via news discourse. It analyzes 119 news articles about refugees from the weekly Reporter and 79 news articles from the weekly Demokracija, which are both self-described as right-wing-oriented political weeklies, and deconstructs the discursive mechanisms which construct the refugees as Muslim immigrants and as a threat to "our" freedoms. The article suggests that two key points of extreme right discourses, migration and Islam, are united on the topic of refugees, which results in the representing of refugees as "alien" to the host, i.e. "our", country. The aim of the article is to reveal the implementation of the populist policy in news discourses. This policy is based on authoritarianism, militarism, nativism and ethnic nationalism, the culturalisation of economic policy and on the techniques of arousing disgust and hatred instead of compassion. The article notes that Islamophobia and extreme populist discourses, which are being spread via the news discourse, replace the biological with the cultural, but also refugees with Muslim immigrants, which gives us a new form of cultural racism. This results in the emergence of new ways of articulation of the "us" community - European civilization vs Islam, whereby "us-ness" against Islam immigrants is strengthened in the modern era and becomes the core of nationalist communities. The article shows that media discourse in Reporter and Demokracija is a culturalized political discourse, since it represents the cultural division between national citizens on one side and cosmopolitan cultural elites and Muslim immigrants on the other as the main division in European countries. This is a new rhetoric of exclusion, which is a characteristic of the populist discourses that Reporter and Demokracija reproduce, and of right-wing politics in general. The article concludes that a new hegemonic shift is occurring - ideas which were once dealt with on the extreme right end of the political spectrum are now permeating mainstream discourses, and this explains the rise and the strengthening of extreme populism as a new cultural racism, reproduced in journalism. 